\title{
Physical activity, cardiorespiratory fitness, and metabolic syndrome in adolescents: A cross- sectional study
}

\author{
Antonio Stabelini Neto ${ }^{1 *}$, Jeffer E Sasaki ${ }^{2}$, Luis PG Mascarenhas ${ }^{3}$, Margaret CS Boguszewski ${ }^{3}$, Rodrigo Bozza ${ }^{4}$,
} Anderson Z Ulbrich ${ }^{4}$, Sergio G da Silva ${ }^{4}$ and Wagner de Campos ${ }^{4}$

\begin{abstract}
Background: In adults, there is a substantial body of evidence that physical inactivity or low cardiorespiratory fitness levels are strongly associated with the development of metabolic syndrome. Although this association has been studied extensively in adults, little is known regarding this association in adolescents. The aim of this study was to analyze the association between physical activity and cardiorespiratory fitness levels with metabolic syndrome in Brazilian adolescents.

Methods: A random sample of 223 girls (mean age, $14.4 \pm 1.6$ years) and 233 boys (mean age, $14.6 \pm 1.6$ years) was selected for the study. The level of physical activity was determined by the Bouchard three-day physical activity record. Cardiorespiratory fitness was estimated by the Leger 20-meter shuttle run test. The metabolic syndrome components assessed included waist circumference, blood pressure, HDL-cholesterol, triglycerides, and fasting plasma glucose levels. Independent Student $t$-tests were used to assess gender differences. The associations between physical activity and cardiorespiratory fitness with the presence of metabolic syndrome were calculated using logistic regression models adjusted for age and gender.

Results: A high prevalence of metabolic syndrome was observed in inactive adolescents (males, 11.4\%; females, 7.2\%) and adolescents with low cardiorespiratory fitness levels (males, 13.9\%; females, 8.6\%). A significant relationship existed between metabolic syndrome and low cardiorespiratory fitness (OR, 3.0 [1.13-7.94]).

Conclusion: The prevalence of metabolic syndrome is high among adolescents who are inactive and those with low cardiorespiratory fitness. Prevention strategies for metabolic syndrome should concentrate on enhancing fitness levels early in life.
\end{abstract}

\section{Background}

The term metabolic syndrome (MetS) refers to a clustering of cardiovascular risk factors represented by high blood pressure, overweight/obesity, hypertriglyceridemia, low high-density lipoprotein-cholesterol (HDL-C), and glucose intolerance. The diagnosis of MetS in adults, and recently in children and adolescents, is established when three or more of the five individual elements exist together in the same subject $[1,2]$.

Various diagnostic criteria have been proposed by different organizations over the past decade. To standardize

\footnotetext{
* Correspondence: asneto@uenp.edu.br

${ }^{1}$ Center for Health Sciences, Universidade Estadual do Norte do Paraná, Jacarezinho, Brazil

Full list of author information is available at the end of the article
}

the MetS definition, a recent joint scientific statement [3] proposed specific criteria for the clinical diagnosis of MetS in adults. However, there was no consensus regarding the diagnostic criteria for MetS in the pediatric population. Therefore, diagnostic criteria used in adults have been adapted for children and adolescents [4]. These criteria are based on reference values from the NCEP Pediatric Panel report, the American Diabetes Association statement on type 2 diabetes in children and adolescents, and the updated Task Force report on the diagnosis and management of hypertension in childhood [4].

In adults, MetS is associated with a significantly elevated risk of coronary heart disease [5] and diabetes mellitus [6], while in children and adolescents there is a direct relationship between the number of cardiovascular 
risk factors and the severity of asymptomatic atherosclerosis [7]. There is a substantial body of evidence associating physical inactivity or low cardiorespiratory fitness with the development of MetS in adults [8-10]. This association in children and adolescents is controversial.

However, evidence suggests that sedentary behavior, low levels of physical activity, and cardiorespiratory fitness in youth track into adulthood [11]. Similarly, metabolic risk factors also appear to track over time [12], and may predispose young people to disease later in life [13].

Based on this information, the aim of this study was to estimate the prevalence of MetS and to analyze the association between physical activity and cardiorespiratory fitness with MetS in a random sample of Brazilian adolescents.

\section{Methods \\ Sample}

This cross-sectional study was carried out in Curitiba, Paraná, Brazil. The city of Curitiba has a population of $1,678,965$ inhabitants with a human development index of 0.763 . The sample size consisted of school children registered in the education system (approximately 45,000 students). The following parameters were used to estimate the sample size: an error of 5\%; an estimated MetS prevalence of $20 \%$; a design effect of 1.5 ; a $95 \%$ confidence interval; and an additional $10 \%$ for losses and refusals. A conglomerate sample of 456 adolescents (223 girls [49\%] and 233 boys [51\%]) was evaluated. The schools were randomly selected, and the proportion of students was established according to the number of students in each of the nine administrative areas of the city (Santa Felicidade 6.6\%; Matriz, 12.3\%; Boa Vista, 14.7\%; Cajuru, 12\%; Portão, 10.6\%; Boqueirão, 13.1\%; Bairro Novo, 9.6\%; Pinheirinho, 9.5\%; and CIC, 11.6\%). Data collection took place between April and November 2009.

All subjects completed a physical activity questionnaire. Height, weight, blood pressure, cardiorespiratory fitness, and lipid profiles were measured in all subjects. Only students between 10 and $<18$ years of age were included in the analyses. Exclusion criteria were the known presence of diabetes and the use of medications that alters blood pressure, glucose, or lipid metabolism.

Written informed consent was obtained from the parent or legal guardian of the adolescent after being given a detailed written explanation of the aims of the study, and the possible hazards, discomfort, and inconvenience. All subjects were given the option to drop out at any time without consequence. This research was approved by the Ethics Committee of the Federal University of Paraná (Resolution 196/96). All procedures and methods in this study conformed to the ethical guidelines established by the World Medical Association's Declaration of Helsinki and the subsequent revisions.

\section{Anthropometric measures}

Physical measurements were obtained by trained research assistants after blood sample was taken. The body height was measured without shoes to the nearest $0.1 \mathrm{~cm}$ with a transportable stadiometer (Ottoboni HM-210D; Ottoboni, Rio de Janeiro, RJ, Brazil). Body weight was measured in light clothing to the nearest $0.1 \mathrm{~kg}$ with a calibrated beam balance scale (Toledo 2096 PP; Toledo do Brasil, São Bernardo do Campo, SP, Brazil). Waist circumference was measured at the end of gentle expiration, midway between the lower rib margin and the iliac crest.

\section{Blood pressure}

Blood pressure (BP) was measured by trained technicians before the blood sampling procedure. The BP measurement was performed according to the method described in The Fourth Report on the Diagnosis, Evaluation, and Treatment of High Blood Pressure in Children and Adolescents [14]. The students were asked to rest in the sitting position for 5-10 min prior to the BP assessment. The systolic blood pressure (SBP) and diastolic blood pressure (DBP) were measured in the right arm using a sphygmomanometer of mercury column. Two measurements were obtained after 5 and $10 \mathrm{~min}$ of rest. The mean of the two measurements was considered. If the two measurements differed by $>2 \mathrm{mmHg}$, a third measure was obtained.

\section{Blood sampling}

Blood samples were obtained by trained and certified nurses between 8:00 and 9:00 AM following an overnight fast. After the blood samples were collected, the subjects were served breakfast, then continued with the physical and fitness measurements. The samples were immediately centrifuged and the serum or plasma separated and placed on dry ice for shipment back to the chemistry laboratory. A single certified laboratory was used for all analyses. HDL-C, triglycerides, and glucose levels were analyzed by colorimetric assay on a randomaccess Spectrum CCX analyzer (Abbott Diagnostics, Abbott Park, IL, USA).

\section{MetS definitions}

We used the age-modified standards of the ATP III MetS criteria published previously [4] and utilized in others research $[15,16]$. Abdominal obesity was considered as a waist circumference $\geq 90^{\text {th }}$ percentile for age and gender [17]. High blood pressure was considered as a SBP and/or DBP $>90^{\text {th }}$ percentile by age, gender, and height based on published reference data [14]. Adolescents were considered to have excessive total triglycerides levels if blood concentrations were $\geq 110 \mathrm{mg} / \mathrm{dL}$. HDL-C levels were considered low at a level of $\leq 40 \mathrm{mg} / \mathrm{dL}$, while fasting blood glucose levels $\geq 110 \mathrm{mg} / \mathrm{dL}$ were considered indicative of hyperglycemia [4]. MetS was diagnosed when three or more of the five individual elements were present together in the same individual. 


\section{Physical activity}

The Three-Day Physical Activity Record [18] was used to self-record daily activities over 3 days ( 2 weekdays and 1 weekend day). The daily activities were recorded by adolescents in 15-min segments throughout the day on a scale divided into 9 categories of physical activity (1-2, sedentary activity [lying down and seated]; 3-5, light activity [taking a shower, cooking, taking a walk, and light manual work]; 68 , moderate activity [sports or leisure activities and moderate manual work; 9 , vigorous activity [intense manual work and intense sport or leisure activities]). In this selfreport instrument, the subject fills in the boxes corresponding to physical activities performed during the specific time periods.

The questionnaires were self-completed in the classroom with orientation from the researcher. The time spent doing exercises with moderate-to-vigorous intensity ( $\geq 6$ in a physical activity scale) was recorded, then used to determine the total moderate-to-vigorous physical activity (MVPA) expressed in minutes per day. The mean value from the 3 days was considered for the analysis.

The reproducibility of this instrument was reported to be $r=0.91$ in subjects from 10 years of age [18], and was validated in adolescents using the technique of double-labeled water [19].

\section{Cardiorespiratory fitness}

Cardiorespiratory fitness was estimated using the 20-meter shuttle run test, as described by Leger et al. [20]. The test was carried out in a gym with a plane surface. The required speed was continuously increased every minute by $0.5 \mathrm{~km} / \mathrm{h}$. Subjects kept the required speed by completing every 20-meter stage within the sound of two beep sounds. The interval between these beeps was reduced every minute in order to elicit the speed increments. The velocity in the last stage completed by each subject was recorded and used to calculate the $\mathrm{VO}_{2 \text { máx }}$ in $\mathrm{ml} . \mathrm{kg}^{-1} \mathrm{~min}^{-1}$ according to the equation validated by Léger et al. [20], as follows: $\mathrm{VO}_{2 \text { máx }}=31.025+3.238^{*}$ velocity $-3.248^{*}$ age + $0.1536^{*}$ velocity"age. The authors reported a relationship to directly measured $\mathrm{VO}_{2 \text { máx }}$ of 0.84 and a test-retest correlation of 0.98 .

\section{Statistical procedures}

Descriptive data are shown as the mean and standard deviation. The Kolmogorov-Smirnov test was used to verify the normality of the physical activity and physical fitness distribution data. To compare the continuous variables between the genders we used Student's $t$-test, and the chi-squared test was used for categorical variables.

The prevalence of MetS and its components was calculated with respect to different cardiorespiratory fitness and physical activity categories. Fitness levels were determined based on tertiles of cardiorespiratory fitness (boys: low $<46 \mathrm{ml} . \mathrm{kg}^{-1} \mathrm{~min}^{-1}$, moderate $46-51 \mathrm{ml} . \mathrm{kg}^{-1} \mathrm{~min}^{-1}$, and high $>51 \mathrm{ml} . \mathrm{kg}^{-1} \mathrm{~min}^{-1}$; girls: low $<38 \mathrm{ml} . \mathrm{kg}^{-1} \mathrm{~min}^{-1}$, moderate $38-43 \mathrm{ml} \cdot \mathrm{kg}^{-1} \mathrm{~min}^{-1}$, and high $>43 \mathrm{ml} \cdot \mathrm{kg}^{-1} \mathrm{~min}^{-1}$. For physical activity, the thresholds were as follows: inactive $<60 \mathrm{~min}$.day of MVPA; active: $\geq 60$ and $<90 \mathrm{~min} /$ day of MVPA; very active: $\geq 90 \mathrm{~min} /$ day of MVPA.

The associations between physical activity and cardiorespiratory fitness with the diagnosis of MetS were calculated using binary logistic regressions. The outcome variable was the presence of MetS. The exposure variables were: participation in moderate-to-vigorous physical activity (inactive, active, and very active) and $\mathrm{VO}_{2 \max }$ tertiles (low, moderate, and high). The logistic regression models were adjusted for age and gender. The statistical analyses were performed using SPSS (version 15.0 for Windows; Chicago, IL, USA) [21]. A $p$ value $<0.05$ denoted statistical significance.

\section{Results}

Descriptive data by gender are shown in Table 1. Boys had higher levels of height, weight, waist circumference, cardiorespiratory fitness, physical activity, SBP, and glucose than girls $(\mathrm{p}<0.0001$ for all), whereas girls had higher HDL-C values. No differences in age, DBP, and triglycerides levels were observed between genders. The prevalence of MetS was 7.7\% among Brazilian adolescents. The prevalence of MetS in boys (10.2\%) was significantly higher than in girls (5\%; $\mathrm{p}<0.05)$ (Data not shown).

The low HDL-C (33.3\%) was the most prevalent component of the MetS criteria, followed by high blood pressure (21.5\%), hypertriglyceridemia (19.8\%), and hyperglycemia (5.5\%) (Data not shown). The prevalence of individual risk factors by gender is shown in Table 2 . The prevalence of hyperglycemia and low HDL-C in

Table 1 Anthropometric, cardiorespiratory fitness, physical activity, and individual risk factors characteristics of Brazilian adolescents by gender

\begin{tabular}{|c|c|c|c|c|c|}
\hline & \multicolumn{2}{|c|}{$\begin{array}{c}\text { Males } \\
\mathrm{N}=233\end{array}$} & \multicolumn{2}{|c|}{$\begin{array}{l}\text { Females } \\
\mathrm{N}=223\end{array}$} & \multirow[t]{2}{*}{$p^{*}$} \\
\hline & Mean & SD & Mean & SD & \\
\hline Age (years) & 14.6 & 1.6 & 14.4 & 1.6 & ns \\
\hline Height (cm) & 167.1 & 11.6 & 158.8 & 7.5 & $<0.0001$ \\
\hline Weight (kg) & 57.1 & 12.5 & 51.7 & 10.8 & $<0.0001$ \\
\hline Waist circumference $(\mathrm{cm})$ & 70.8 & 8.9 & 65.5 & 7.0 & $<0.0001$ \\
\hline $\mathrm{VO}_{2} \operatorname{máx}\left(\mathrm{ml}^{-1} \mathrm{~kg}^{-1} \mathrm{~min}^{-1}\right)$ & 49.0 & 6.2 & 40.5 & 4.7 & $<0.0001$ \\
\hline MVPA & 136.8 & 103.3 & 75.1 & 82.2 & $<0.0001$ \\
\hline $\mathrm{SBP}(\mathrm{mmHg})$ & 100.7 & 13.9 & 95.1 & 13.2 & $<0.0001$ \\
\hline $\mathrm{DBP}(\mathrm{mmHg})$ & 69.1 & 10.6 & 68.1 & 10.6 & ns \\
\hline HDL-C (mg/dL) & 45.2 & 11.0 & 49.9 & 14.1 & $<0.0001$ \\
\hline Triglycerides (mg/dL) & 89.3 & 41.3 & 85.1 & 34.4 & ns \\
\hline Fasting glucose (mg/dL) & 89.4 & 13.6 & 83.7 & 13.8 & $<0.0001$ \\
\hline
\end{tabular}

Data are means (SD), * Student's $t$-test for differences between gender Abbreviations: MVPA, Moderate-Vigorous Physical Activity; SBP, Systolic blood pressure; DBP, Diastolic blood pressure; ns, non-significant. 
Table 2 Distribution of individual risk factors among Brazilian adolescents by gender

\begin{tabular}{lccccc}
\hline & \multicolumn{2}{c}{$\begin{array}{c}\text { Males } \\
\mathbf{N}=\mathbf{2 3 3}\end{array}$} & \multicolumn{2}{c}{$\begin{array}{c}\text { Females } \\
\mathbf{N}=\mathbf{2 2 3}\end{array}$} & $\mathbf{p}^{*}$ \\
\cline { 2 - 6 } & $\mathbf{\%}$ & $\mathbf{9 5 \%} \mathbf{C l}$ & $\mathbf{\%}$ & $\mathbf{9 5 \%} \mathbf{C l}$ & \\
\hline Large waist circumference & 10.5 & $7-28.5$ & 10.9 & $7.3-15.5$ & ns \\
High blood pressure & 22.6 & $17.8-28.5$ & 20.3 & $15.4-25.9$ & ns \\
Low HDL-C & 39.2 & $33-45.4$ & 27 & $21.5-33$ & 0.006 \\
Hypertriglyceridemia & 19.8 & $15.1-25.3$ & 19.8 & $15-25.4$ & ns \\
Hyperglycemia & 7.8 & $4.9-11.8$ & 3.2 & $1.5-6.3$ & 0.033 \\
\hline${ }^{*}$ Chi-squared test. & & & & & \\
Abbreviations: 95\% IC, Confidence interval of 95\%; ns, non-significant. &
\end{tabular}

boys was significantly higher than girls. The proportion of subjects who had 1 or more individual risk factors was $77.1 \%$ (Data not shown).

The prevalence of MetS by physical activity and cardiorespiratory fitness levels is shown in Figures 1 and 2 . A higher prevalence of MetS was observed in the inactive adolescents and in the adolescents with low cardiorespiratory fitness $(\mathrm{p}<0.05)$; there was no difference with respect to gender. Significant associations were demonstrated between MetS and cardiorespiratory fitness (Table 3). The subjects with low cardiorespiratory fitness had an odds ratio for MetS of 3 (CI, 1.13-7.94) compared with subjects with high cardiorespiratory fitness. No significant association was observed between MetS and physical activity.

\section{Discussion}

Cardiovascular disease risk factors in children and adolescents have been assessed in many studies. Most studies have looked at a single or a combination of risk factors [22-25]. Several studies have also used diverse definitions of pediatric MetS $[4,26,27]$. There are few studies pertaining to the prevalence of MetS in Brazilian children and adolescents with which to compare. Our data showed that

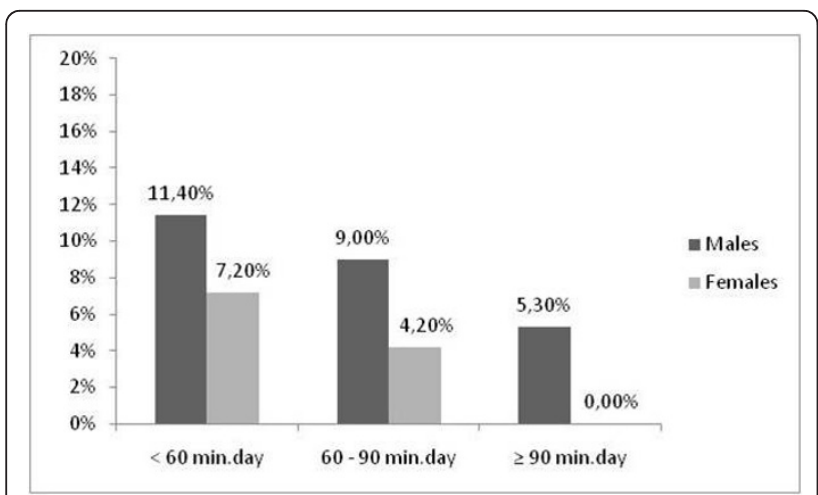

Figure 1 Prevalence of metabolic syndrome according to time participation in moderate-to-vigorous physical activity. ${ }^{*} p<$ 0.05 between the physical activity levels (Chi-squared test).

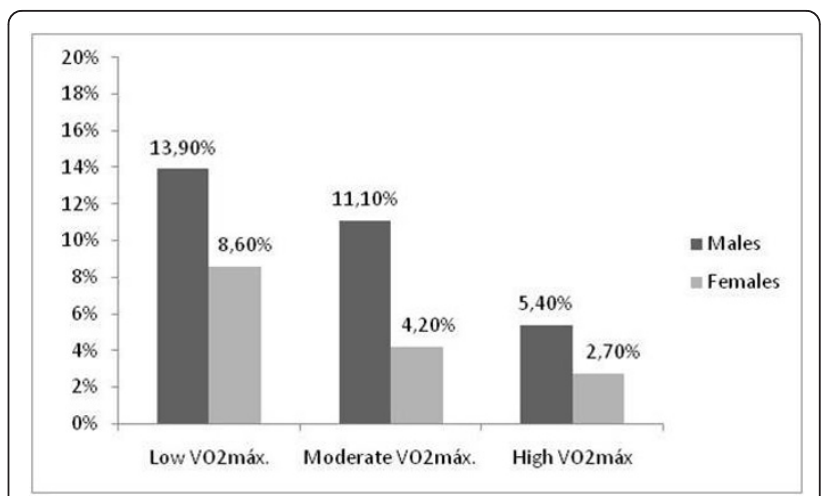

Figure 2 Prevalence of metabolic syndrome according to cardiorespiratory fitness levels. ${ }^{*} p<0.05$ between the cardiorespiratory fitness levels (Chi-squared test).

the prevalence of MetS in Brazilian adolescents (7.7\%) is consistent with previously published studies. Data from these studies suggest that the prevalence of MetS varies between $3 \%$ and $12 \%$ in a representative sample of youth $[4,15,16,28]$.

Rodrigues et al. [29] evaluated 380 subjects (Vitoria, ES, Brazil) and reported a prevalence of MetS in $1.3 \%$ of adolescents. Cavali et al. [30] evaluated 80 obese adolescents (São Paulo, SP, Brazil) and reported a prevalence of 13.7\% using the International Diabetes Federation criteria and $15 \%$ by Jolliffe and Janssen criteria. These studies highlight the need for standardized criteria to diagnose MetS in children and adolescents. Therefore, findings using different diagnostic criteria for MetS should be made with caution.

Data from the NHANES 1999-2002 showed that adolescents with the lowest physical activity level had a significantly increased prevalence of MetS in both genders [31]. In our study, the associations between physical activity and MetS were not significant. This was the case even when we used a continuous score to define MetS (Data not shown). Nevertheless, determining the MetS prevalence by physical activity and cardiorespiratory fitness suggest that adolescents with higher physical activity levels and cardiorespiratory fitness had lower MetS prevalence. Similarly, in the study by Nguyen et al. [32], the odds of MetS among youth in the lowest physical activity group ( $<43 \mathrm{~min}$ of physical activity per day) were five times greater than those in the highest physical activity group (> 103 min per day). Conversely, Pan and Pratt [33] examined the association of MetS with physical activity in 4,450 US adolescents and demonstrated that despite the tendency of a lower prevalence of MetS in active subjects, this association was not statistically significant.

In terms of cardiorespiratory fitness, the associations reported in the present study are supported by previous research. Andersen et al. [34] reported a lower $\mathrm{VO}_{2 \max }$ 
Table 3 Logistic regression of cardiorespiratory fitness and physical activity levels with the metabolic syndrome in Brazilian adolescents

\begin{tabular}{|c|c|c|c|}
\hline & \multirow[b]{2}{*}{$\mathbf{N}$} & \multicolumn{2}{|c|}{$\begin{array}{l}\text { Metabolic syndrome } \\
\text { OR (95\% IC) }\end{array}$} \\
\hline & & non-adjusted & adjusted for age and gender \\
\hline High $V_{2 \text { máx }}\left(3^{\text {rd }}\right.$ tertile $)$ & 152 & 1 & 1 \\
\hline Moderate $\mathrm{VO}_{2 \text { máx. }}\left(2^{\text {nd }}\right.$ tertile) & 154 & $\begin{array}{c}1.96 \\
(0.64-7.08)\end{array}$ & $\begin{array}{c}1.9 \\
(0.70-5.48)\end{array}$ \\
\hline Low VO ${ }_{2 \text { máx. }}\left(1^{\text {st }}\right.$ tertile $)$ & 150 & $\begin{array}{c}3.32^{*} \\
(1.16-7.08)\end{array}$ & $\begin{array}{c}3.0^{*} \\
(1.13-7.94)\end{array}$ \\
\hline $\begin{array}{l}\text { Very active } \\
(\geq 90 \mathrm{~min} / \text { day of MVPA) }\end{array}$ & 56 & 1 & 1 \\
\hline $\begin{array}{l}\text { Active } \\
(\geq 60 \text { and }<90 \mathrm{~min} / \text { day of MVPA) }\end{array}$ & 217 & $\begin{array}{c}1.77 \\
(0.20-5.68)\end{array}$ & $\begin{array}{c}1.15 \\
(0.56-2.37)\end{array}$ \\
\hline Inactive (<60 min/day of MVPA) & 183 & $\begin{array}{c}2.32 \\
(0.29-8.58)\end{array}$ & $\begin{array}{c}1.25 \\
(0.60-2.60)\end{array}$ \\
\hline
\end{tabular}

${ }^{*} \mathrm{p}<0.05$ (Wald test)

Abbreviations: OR, odds ratio; $95 \% \mathrm{IC}$, Confidence interval of $95 \%$.

in adolescents with three or more risk factors. A recent study [35] demonstrated that unfit Azorean Islands adolescents were more likely (OR, 3.414; 95\% CI, 1.15010.129) to be diagnosed with MetS when compared to the fittest adolescents.

Therefore, the evidence suggests that physical activity and cardiorespiratory fitness are important indicators of the risks for developing MetS [34]. Thus, pediatric researchers have investigated how these individual lifestyle components increase the metabolic risk from childhood and adolescence to adulthood [36-38].

In a review of the secular trends in variables associated with the MetS of North American youth, Eisenmann [39] showed that cardiorespiratory fitness and physical activity has not changed in youth in recent decades. McMurray et al. [40] reported a high incidence of MetS in adolescents with a history of low fitness and physical activity. Steele et al. [41] suggested that physical activity and cardiorespiratory fitness influence metabolic risk trough separate pathways. An important distinction between physical activity and cardiorespiratory fitness is intra-individual day-to-day variability; physical activity will undoubtedly vary on a daily basis, whereas cardiorespiratory fitness will remain relatively static, taking time to change. This variability impacts the ability to measure these two variables and consequently influences their relationship with metabolic outcomes [41].

Further, it has been difficult to argue for specific levels of physical activity or fitness in children and adolescents, which could indicate an unhealthy condition [41-43]. However, the optimal amounts of physical activity and cardiorespiratory fitness required for preventing and treating the MetS in children and adolescents is unknown. Therefore, we propose substituting part of the sedentary time with light physical activity, then advancing to moderate-intensity, increasing goals and tailored on individual characteristics, up to an end point represented by daily moderate-to-vigorous intensity program that is sufficient to achieve normalization of the metabolic profile [41-43].

The primary limitation of this study was that MetS outcomes were dependent on our definition of MetS, a problem inherent to the lack of consensus about the criteria for diagnosing MetS in a pediatric population. In addition, the cross-sectional study design does not guarantee the temporal precedence of variables and limit the extrapolation of observations. Another limitation of the study was the use of self-report instruments to measure physical activity. However, the physical activity record is considered a valid instrument for physical activity evaluation [19] and is widely used in studies involving young people [44-47]. A potential factor that may indirectly influence MetS prevalence is socioeconomic status, which was not evaluated in this sample. Therefore, future studies should use socioeconomic status as a control variable when assessing the influence of physical activity and cardiorespiratory fitness on risk of MetS.

Future research should also examine what is the optimal amount of physical activity needed to maximize metabolic health benefits in children and adolescents. In order to facilitate this examination, a standardization of the MetS definition should be further discussed among organizations and experts in the field. Finally, future studies should use both dichotomous and continuous scoring for MetS. In our study, continuous scoring did not result in stronger associations between physical activity and MetS. However, differences in sample size and sample characteristics may result in different associations depending on the selected approach for scoring MetS.

\section{Conclusion}

In summary, our results demonstrate that the prevalence of MetS is higher among Brazilian adolescents who are 
inactive and have low cardiorespiratory fitness, and there was a significant relationship between MetS and cardiorespiratory fitness. This indicates that long-term prevention strategies should be developed to increase physical activity and cardiorespiratory fitness early in life, with the goal of promoting a physically active lifestyle.

\begin{abstract}
Abbreviations
MetS: metabolic syndrome; HDL-C: high-density lipoprotein-cholesterol; BP: blood pressure; SBP: systolic blood pressure; DBP: diastolic blood pressure; MVPA: moderate to vigorous physical activity; SD: standard deviation; OR: odds ratio; 95\% Cl: confidence interval of 95\%; ns: non-significant.
\end{abstract}

\section{Author details}

${ }^{1}$ Center for Health Sciences, Universidade Estadual do Norte do Paraná, Jacarezinho, Brazil. ${ }^{2}$ Deparment of Kinesiology, University of Massachusetts, Amherst, USA. ${ }^{3}$ Departament of Pediatrics, Universidade Federal do Paraná, Curitiba, Brazil. ${ }^{4}$ Departament of Physical Education, Universidade Federal do Paraná, Curitiba, Brazil.

\section{Authors' contributions}

ASN was the principal researcher responsible for the collection, analysis, and interpretation of data, as well as for drafting the manuscript. RDB, AZU, and LPGM were involved in analysis and interpretation of data and also in the critical revision of the paper. MCSB, SGS, WC, and JES were involved in revising the manuscript critically for important intellectual content. All authors read and approved the final manuscript.

\section{Competing interests}

The authors declare that they have no competing interests.

Received: 27 January 2011 Accepted: 30 August 2011

Published: 30 August 2011

\section{References}

1. National Cholesterol Education Program (NCEP) Expert Panel on Detection, Evaluation, and Treatment of High Blood Cholesterol in Adults (Adult Treatment Panel III): Executive Summary of the Third Report of The National Cholesterol Education Program (NCEP) Expert Panel on Detection, Evaluation, ad Treatment of High Blood Cholesterol In Adults (Adult Treatment Panel III). JAMA 2001, 285:2486-2497.

2. Ford ES, Li C: Defining the metabolic syndrome in children and adolescents: Will the real definition please stand up? J Pedriatr 2008, 152:160-4.

3. Alberti KGMM, Eckel SM, Grundy SM, Zimmet PZ, Cleeman Jl, Donato KA, et al: Harmonizing the metabolic syndrome: A Joint Statement of the International Diabetes Federation Task Force on Epidemiology Prevention. Circulation 2009, 120:16401645.

4. Cook S, Weitzman M, Auinger P, Nguyen M, Dietz WH: Prevalence of a metabolic syndrome phenotype in adolescents: findings from the Third National Health and Nutrition Examination Survey, 1988-1994. Arch Pediatr Adolesc Med 2003, 157:821-827.

5. Hitsumoto T, Makahashi M, Lizuka T, Shirai K: Relationship between metabolic syndrome and early stage coronary atherosclerosis. Atheroscler Thromb 2007, 14:294-302.

6. Haffner SM, Valdez RA, Hazuda HP: Prospective analysis of the insulinresistance syndrome (syndrome X). Diabetes 1992, 41:715-722.

7. Berenson GS, Wattigney WA, Tracy R: Atherosclerosis of the aorta and coronary arteries and cardiovascular risk factors in persons 6 to 30 years and studied at necropsy (the Bogalusa Heart Study). Am J Cardiol 1992, 70:851-8.

8. Erikson J, Taimela S, Koivisto VA: Exercise and the metabolic syndrome. Diabetologia 1997, 40:125-135.

9. Kullo IJ, Hensrud DD, Allison TG: Relation of low cardiorespiratory fitness to the metabolic syndrome in middle-aged men. Am J Cardiol 2002, 90:795-797.
10. Johnson $J$, Slentz CA, Houmard JA, Samsa GP, Duscha BD, Aiken LB: Exercise training amount and intensity effects on metabolic syndrome (from studies of a targeted risk reduction intervention through defined exercise). Am J Cardiol 2007, 100:1759-1766.

11. Malina RM: Tracking of physical activity and physical fitness across the lifespan. Res Q Exerc Sport 1996, 67:S48-S57.

12. Chen W, Srinivasan SR, Li S, Xu J, Berenson GS: Clustering of long-term trends in metabolic syndrome variables from childhood to adulthood in Blacks and Whites: The Bogalusa Hearth Study. Am J Epidemiol 2007, 166:527-533.

13. Hasselstrøm H, Hansen SE, Froberg K, Andersen LB: Physical fitness and physical activity during adolescence as predictors of cardiovascular disease risk in young adulthood. Int J Sports Med 2002, 23:s27-31.

14. National High Blood Pressure Education Program Working Group High Blood Pressure in Children and Adolescents: The fourth report on the diagnosis, evaluation, and treatment of high blood pressure in children and adolescents. Pediatrics 2004, 114(2):555-76.

15. Duncan GE, Li SM, Zhou X: Prevalence and trends of metabolic syndrome phenotype among U.S. adolescents, 1999-2000. Diabetes Care 2004, 27:2438-2443.

16. Kranz S, Mahood LJ, Wagstaff DA: Diagnostic criteria patterns of U.S. children with metabolic syndrome: NHANES 1999-2002. Nutr J 2007 6:1-9.

17. Freedman DS, Serdula MK, Srinivasan SR, Berenson G: Relation of circumferences and skinfold thicknesses to lipid and insulin concentrations in children and adolescents: the Bogalusa Heart Study. Am J Clin Nutr 1999, 69:308-317.

18. Bouchard CA, Tremblay C, Leblanc G, Lortie R, Savard R, Theriault G: A method to assess energy expenditure in children and adults. Am J Clin Nutr 1983, 37:461-7.

19. Bratteby LE, Sandhagen B, Fan H, Samuelson G: A 7-day activity diary for assessment of daily energy expenditure validated by the doubly labeled water method in adolescents. Eur J Clin Nutr 1997, 51:585-591.

20. Léger LA, Mercier D, Gadoury C, Lambert J: The multistage 20-meter shuttle run test for aerobic fitness. J Sports Sci 1988, 6:93-101.

21. Statistical package for the social science (SPSS) version 13.0: Manual de utilização do Software. Disponível em 2006 [http://www.spss.com], Acesso em maio de.

22. Guerra S, Duarte JA, Mota J: Physical activity and cardiovascular disease risk factors in schoolchildren. Eur Physical Educ Rev 2001, 7:269-281.

23. Ribeiro JC, Guerra S, Oliveira J, Teixeira-Pinto A, Twisk JWR, Duarte JA, Mota J: Physical activity and biological risk factors clustering in pediatric population. Prev Med 2004, 39:596-601.

24. Bouziotas C, Koutedakis Y, Nevill A, Ageli E, Tsigilis N, Nikolaou A, Nakou A: Greek adolescents, fitness, fat intake, activity, and coronary heart disease risk. Arch Dis Child 2004, 89:41-44.

25. Guedes DP, Guedes JERP, Barbosa DS, Oliveira JA, Stanganelli LCR: Fatores de risco cardiovasculares em adolescentes: indicadores biológicos e comportamentais. Arq Brás Cardiol 2006, 86:439-50.

26. Weiss R, Dziura J, Burgert TS, Tamborlane W, Taksali SE, Yechel CW, et al: Obesity and the metabolic syndrome in children and adolescents. $N$ Engl J Med 2004, 350:2362-2374

27. Jollife CJ, Janssen I: Development of age-specific adolescent metabolic syndrome criteria that are linked to the Adult Treatment Panel III and International Diabetes Federation Criteria. J Am Coll Cardiol 2007, 49:891-8.

28. Ferranti SD, Gauvreau K, Ludwig DS, Neufeld EJ, Newburger JW, Rifai N: Prevalence of the metabolic syndrome in American adolescents: findings from the Third National Health and Nutrition Examination Survey. Circulation 2004, 110:2494-2497.

29. Rodrigues AN, Perez AJ, Pires JGP, Carletti L, Araújo MTM, Moyses MR, Bissoli NS, Abreu GR: Cardiovascular risk factors, their associations and presence of metabolic syndrome in adolescents. J Pediatr 2009, 85:55-60.

30. Cavali MLR, Escrivão MAMS, Brasileiro RS, Taddei JAAC: Síndrome metabólica: comparação de critérios diagnósticos. J Pediatr 2010, 86(4):325-330

31. Kelishadi REM, Gouya MM, Adeli K, Ardalan G, Gheiratmand R, Majdazadeh $R$, et al: Factors associated with the metabolic syndrome en a national sample of youths: CASPIAN Study. Nutrition, Metab CardiovasC Dis 2008, 18:461-470. 
32. Nguyen THHD, Tang HK, Kelly P, Ploeg HPV, Dibley MJ: Association between physical activity and metabolic syndrome: a cross sectional survey in adolescents in Ho Chi Minh City, Vietnam. BMC Public Health 2010, 10:1-9.

33. Pan Y, Pratt CA: Metabolic syndrome and its association with diet and physical activity in US adolescents. J Am Diet Assoc 2008, 108:276-286.

34. Andersen LB, Wedderkopp N, Hansen HS, Cooper AR, Froberg K: Biological cardiovascular risk factors cluster in Danish children and adolescents: the European Youth Heart Study. Prev Med 2003, 37:363-7.

35. Moreira C, Santos R, Vale S, Soares-Miranda L, Marques Al, Santos PC, Mota J: Metabolic syndrome and physical fitness in a sample of Azorean adolescents. Metabolic Syndrome and Related Disorders 2010, 8(5):443-449.

36. Twisk JWR, Kemper HCG, Van Mechelen W: Tracking of activity and fitness and the relationship with cardiovascular disease risk factors. Med Sci Sports Exerc 2000, 32:1455-1461.

37. Katzmarzyk PT, Perusse L, Malina RM: Stability of indicators of the metabolic syndrome from childhood and adolescence to young adulthood: the Quebec Family Study. J Clin Epidemiol 2001, 54:190-195.

38. Ferreira I, Twik JWR, Van Mechelen W, Kemper HCG, Stehouwer CDA: Current and adolescent levels of cardiopulmonary fitness are related to large artery properties at age 36: the Amsterdam growth and health longitudinal study. Eur J Clin Invest 2002, 32:723-731.

39. Eisenmann JC: Secular trends in variables associated with the metabolic syndrome of North American children and adolescents: A Review and Synthesis. Am J Human Biol 2003, 15:786-794.

40. McMurray RG, Bangdiwala SI, Harrell JS, Amorim LD: Adolescents with metabolic syndrome have history of low fitness and physical activity levels. Dynamic Med 2008, 7(5):1-6.

41. Steele RM, Brage S, Corder K, Wareham NJ, Ekelund U: Physical activity, cardiorespiratory fitness, and the metabolic syndrome in youth. J Appl Physiol 2008, 105:342-351.

42. Steinberger J, Daniels SR, Eckel RH, Hayman L, Lustig RH, Mccrindle B, Mietus-Snyder ML: Progress and challenges in metabolic syndrome in children and adolescents. Circulation 2009, 119:628-647.

43. Brambilla P, Pozzobon G, Pietrobelli A: Physical activity as the main therapeutic tool for metabolic syndrome in childhood. Int J Obesity 2011, 35:16-28.

44. Huang Y, Malina RM: Physical activity and correlates of estimated energy expenditure in Taiwanese adolescents 12-14 years of age. Am J Hum Biol 1996, 8:225-36.

45. Bratteby LE, Sandhagen B, Lötborn M, Samuelson G: Daily energy expenditure and physical activity assessed by an activity diary in 374 randomly selected 15-year-old adolescents. Eur J Clin Nutr 1997, 51:592-6.

46. Eisenmann JC, Katzmarzyk PT, Perusse L, Bouchard C, Malina RM: Estimated daily energy expenditure and blood lipids in adolescents: The Quebec Family Study. J Adolesc Health 2003, 33:147-53.

47. Guedes DP, Guedes JERP, Barbosa DS, Oliveira JA: Dispêndio energético diário e níveis de lipídeos-lipoproteínas plasmáticos em adolescentes. Rev Bras Med Esporte 2007, 13(2):123-128.

\section{Pre-publication history}

The pre-publication history for this paper can be accessed here: http://www.biomedcentral.com/1471-2458/11/674/prepub

\section{doi:10.1186/1471-2458-11-674}

Cite this article as: Stabelini Neto et al:: Physical activity, cardiorespiratory fitness, and metabolic syndrome in adolescents: A cross-sectional study. BMC Public Health 2011 11:674.

\section{Submit your next manuscript to BioMed Central and take full advantage of:}

- Convenient online submission

- Thorough peer review

- No space constraints or color figure charges

- Immediate publication on acceptance

- Inclusion in PubMed, CAS, Scopus and Google Scholar

- Research which is freely available for redistribution 